\title{
DRY ICE COMPACTION IN PISTON EXTRUSION PROCESS
}

\author{
Jan GÓRECKI*, Ireneusz MALUJDA*, Krzysztof TALAŚKA*, Dominik WOJTKOWIAK*
}

${ }^{*}$ Chair of Basics of Machine Design, Faculty of Machines and Transport,

Poznan University of Technology, ul. Piotrowo 3, 60-965 Poznań, Poland

jan.gorecki@put.poznan.pl, ireneusz.malujda@put.poznan.pl, krzysztof.talaska@put.poznan.pl, dominik.wojtkowiak@put.poznan.pl

received 6 June 2017, revised 5 December 2017, accepted 8 December 2017

\begin{abstract}
The article presents the results of research on the effect of extrusion tube geometry on the axial force being the key parameter of the dry ice piston extrusion process. The tests were carried out with the experimental set-up based on a cylindrical extrusion tube used alone and supplemented with reducer (orifice). The focus of the experiments was to determine the effect of compression tube reducer on the value of the force of resistance FOP in the dry ice compression process. Its value can subsequently be used as the basis for establishing guidelines for designing and building machines for compression and pelletizing of dry ice.
\end{abstract}

Key words: Dry Ice, Carbon Dioxide, Compaction, Agglomeration Process, Extrusion Tube Reducer

\section{INTRODUCTION}

Waste materials generated during production processes can be recovered and reused, for example as raw materials. An example of such materials is carbon dioxide generated in production of ammonia compounds (Chen et al., 2014). The amount of carbon dioxide generated in these processes is the highest on a percentage basis among all other sources of carbon dioxide emissions (Fig. 1). Carbon dioxide is liquefied through compression and in this form it can be stored for further processing. The amounts of carbon dioxide generated in production processes often exceeds own needs of the factor. Hence, the surplus amounts are often supplied to other companies (Chen et al., 2014; Vansant, 2013)

Expansion of liquid carbon dioxide produces carbon dioxide snow (Liu et al., 2012; Liu et al., 2010). The product has a temperature of $-78.8^{\circ} \mathrm{C}$ and sublimates at room temperatures (Chen et al., 2014; Masa et al., 2016; Mazzoldi et al., 2008; Uhlmann et al., 2010). This is why it is popularly known as dry ice. Maintaining low temperature accompanied with sublimation at normal temperatures make it particularly suitable for food industry applications (including dry ice blasting, disinfection in the food production, carbonating of water, low temperature storage of food products, etc.) (Dong et al., 2012; Li et al., 2016; Liu and Calvert et al., 2012; Liu and Hirama et al., 2012; Masa et al., 2016; Otto et al., 2011; Spur, 1999; Ulhmann et al., 2010; Witte et al., 2017; Yamaguchi et al., 2011).

Dry ice snow can be then densified (compacted) to reduce storage volume and slow down the process of sublimation. Compression extends the time for which dry ice remains in solid phase thus improving the characteristics desired in refrigeration applications (Chen et al., 2014; Górecki et al., 2015 and 2016; Masa et al., 2016).

Dry ice compaction machines are most often based on hydraulic or crankshaft mechanisms. The review of available sources does not provide sufficient data needed for a detailed analysis of the dry ice extrusion process. Such analysis is indis- pensable for evaluation of the process itself and to put forward solutions to improve its efficiency.

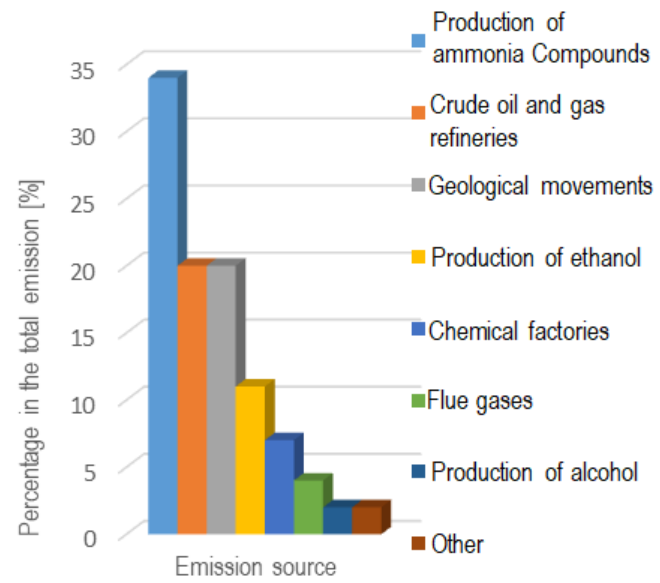

Fig. 1. Main sources of $\mathrm{CO}_{2}$ (Spur, 1999)

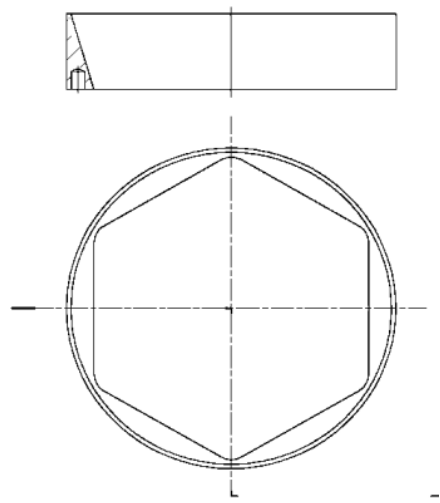

Fig. 2. Extrusion tube reducer

The present research concerns piston extrusion technique implemented with a specifically designed and built machine including 
a multi-channel die and extrusion tube assembly. The paper focuses on the results of testing the compression tube reducer (Fig. 2), described in the patent application No. P.419432 which is an important part of the extrusion assembly having an effect on the compression efficiency. This concerns in particular reduction of the resisting surface area $S_{P P}$ (Fig. 4).

\section{DESIGN OF EXTRUSION TUBE ASSEMBLY USED IN THE PISTON TYPE EXTRUSION MACHINE}

The design of the extrusion tube used in the analysed piston extrusion machine is presented in Fig. 3. The analysed dry ice snow compression method features a sequence of operations performed in a loop. In the first step the snow particles 5 are introduced into the cylindrical tube 2 of $D_{K}$ diameter where they are compressed through piston displacement 1 . The process of compression continues until the resistance force $F_{O P}$ caused by friction and shaping of the pellet in the die 3 equals the force $F_{t}$ applied to the piston 1. In the next step the compacted material moves through the die plate until the piston has reached its end position at which point it starts to reciprocate to the initial position.

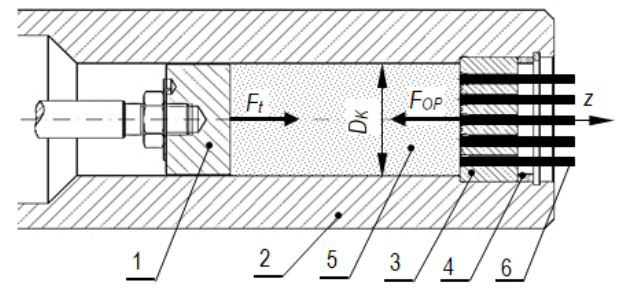

Fig. 3. Piston-type extrusion assembly 1 - piston, 2 - extrusion tube, 3 - multi-channel die, 4 - spacing ring, 5 - dry ice snow, 6 - compressed dry ice snow

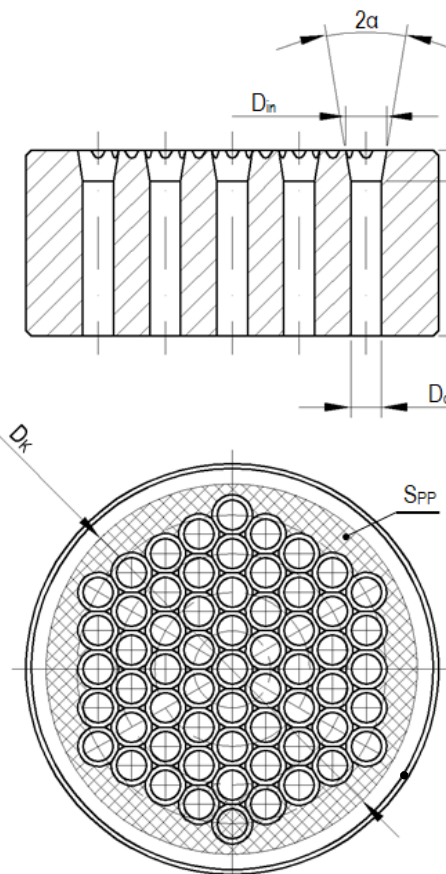

Fig. 4. Multi-channel die, $D_{\text {in }}$ - channel inlet diameter, $D_{\text {out }}$ - channel outlet diameter, a - length of barrel section, $b$ - length of conical section, $2 a-$ angle of convergence of the conical section, $D_{K}$ - extrusion chamber diameter, $\mathrm{S}_{\mathrm{PP}}$ - area of resisting surface
The efficiency of the piston extrusion process depends primarily on the design of the die plate including partly cylindrical and partly conical channels (Fig. 4). The die geometry influences the movement resistance as well as the final shape of the pellet. There are 61 channels, each comprising a conical section of length $b$ and $2 \alpha$ angle of convergence followed by cylindrical (barrel) section of length $a$ and diameter $D_{\text {out. The die channels }}$ are all arranged within a hexagon with sides the length of $e$. Since the die is mounted within a cylindrical extrusion tube (No. 2 in Fig. 3) the die plate surface $S_{P P}$ is perpendicular to axis $Z$.

In order to determine the minimum external force $F_{t}$ applied on the piston to effect densification of dry ice snow the test procedure described in literature was used (Drzymała, 1988; Górecki et al., 2013; Malczewski, 1992). The test apparatus was MTS strength tester, model Insight $50 \mathrm{kN}$ which allowed recording the force and displacement values at $10 \mathrm{~Hz}$ frequency.

a)

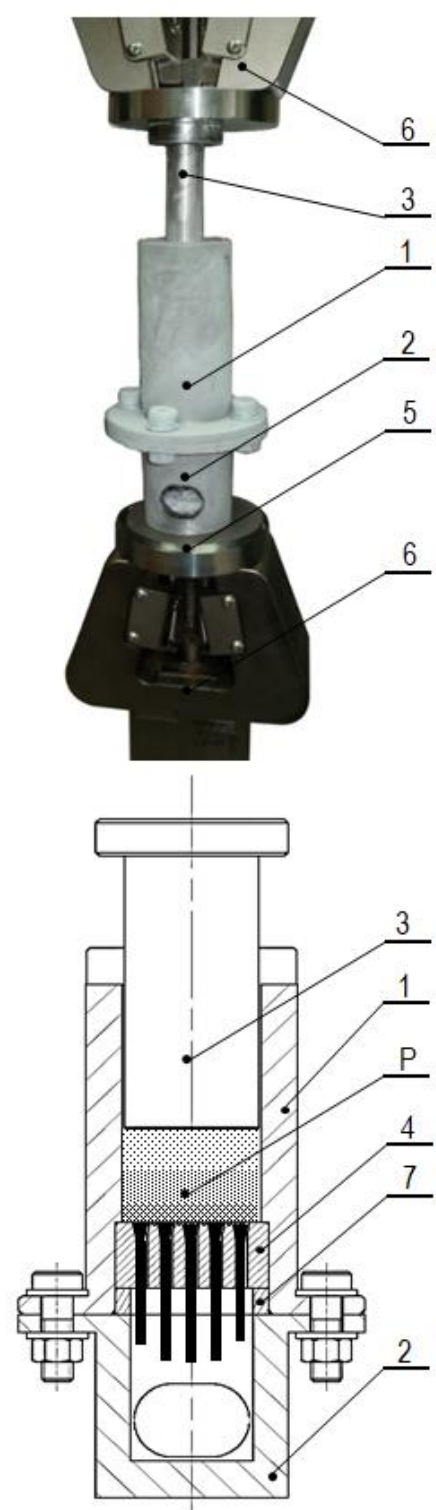

Fig. 5. Test set-up a) grips of the MTS strength tester including the test assembly and alignment jig, b) cross-section of the test assembly 1 - cylindrical extrusion tube, 2 - base of the test assembly, 3 - piston, 4 - multi-channel die plate 5 - right-angle jig, 6 - grips of the strength tester, 7 - spacing ring, $\mathrm{P}$ - compressed dry ice snow (Górecki et al., 2013) 


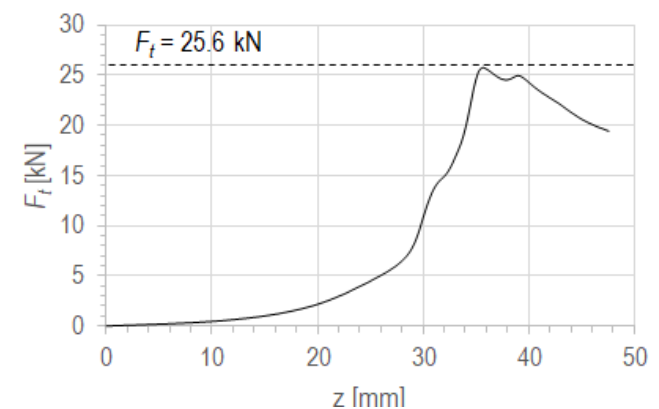

Fig. 6. Dry ice snow compression curve

in a multi-channel die extrusion system

A special test assembly was used in the tests (Fig. 5). In order to minimize the measurement error due to eccentric mounting of the compression head, the grips were equipped with a rightangle jig to align the compression force in the direction perpendicular to the specimen cross-section 5 .

Before starting the test the compression chamber 1 was filled with crushed dry ice. Subsequently the piston 3 was inserted into the extrusion chamber 2 . The test set-up was complete with the test assembly fitted in the grips of the strength tester. The scale was zeroed and the procedure was started by lowering the piston 3 downwards at a constant speed. When $F_{t}$ reached the level of $F_{O P}$ the material started being pushed through the multi-channel die 4.

The test was repeated ten times and the results were averaged and presented as compression curves representing the change of force $F_{t}$ as a function of piston displacement $Z$ (Fig. 6).

The average force $F_{t}$ is $25.6 \mathrm{kN}$.

\section{COMPRESSION TUBE REDUCER}

The value of $F_{O P}$ force is influenced by the geometric parameters of the parts making up the compression chamber. One of them is the compression chamber reducer (Fig. 7, 8). The purpose of this piece is to reduce the area of the resistance surface SpP.

a)

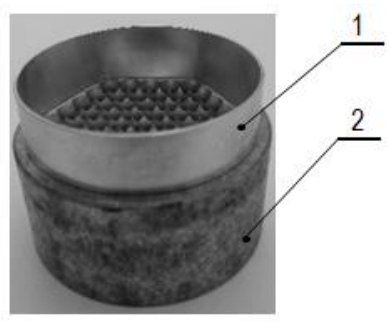

b)

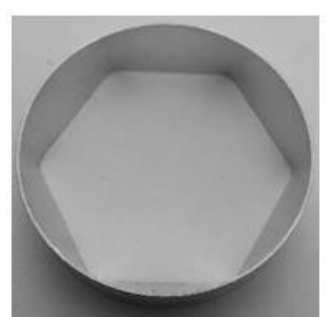

Fig. 7. Assembly comprising the multi-channel die plate and compression tube reducer a) entire assembly, b) stress concentration reducer: 1 - reducer piece, 2 - multi-channel die plate
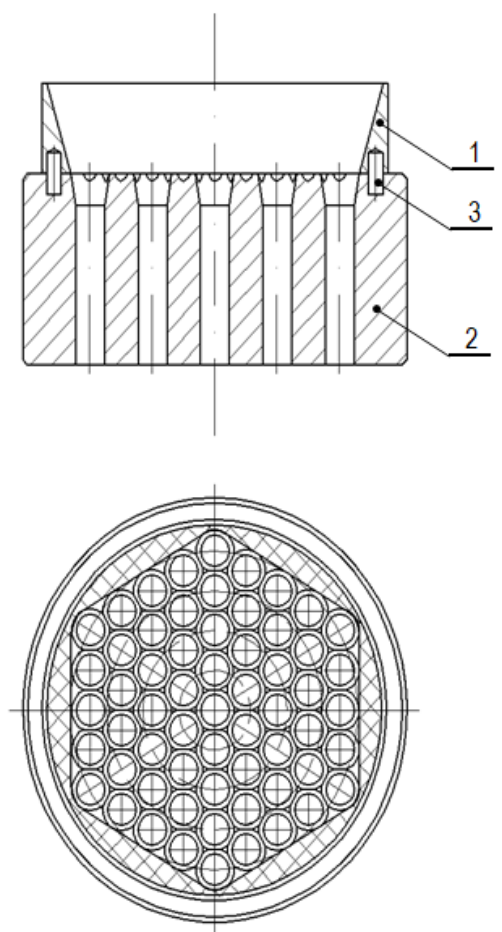

Fig. 8. Assembly comprising the multi-channel die plate and compression tube reducer: 1 - compression tube reducer, 2 - multi-channel die plate, 3 - locating pin, SPP - resisting surface (P.419432)

Since the shape of the reducer is not circularly symmetric (due to circular to hexagonal shape transition) two locating pins 3 were used to align the elements (Fig. 8).

The assembly obtained in this way can be fitted in the tube in which dry ice snow is compressed by a crank-driven piston (Fig. 9).

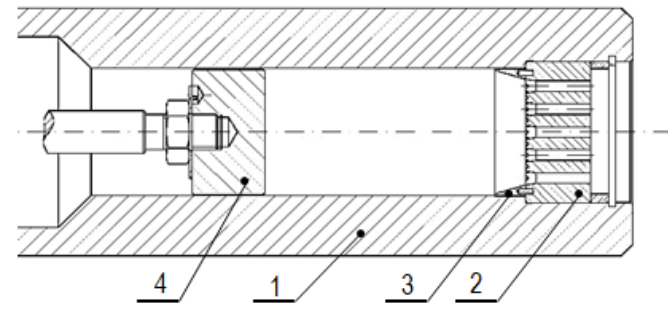

Fig. 9. The processing assembly of the piston extrusion machine: 1 - cylindrical extrusion tube, 2 - multi-channel die plate, 3 - compression tube reducer, 4 - piston (P.419432)

Reduction of the resisting surface SpP obtained by fitting the reducer affects the experimentally determined force applied on the piston $F_{t}^{\prime}$.

The test procedure was the same as described in the previous chapter. The test set-up was also the same (Fig. 10a) except that this time it included the compression tube reducer assembly besides the multi-channel die plate 4, 5 (Fig. 10b).

Based on the above described kinematic structure the design of the research

The test results were averaged and presented as a compression curve representing the change of force $F_{t}^{\prime}$ as a function of piston displacement $z$ (Fig. 11). 


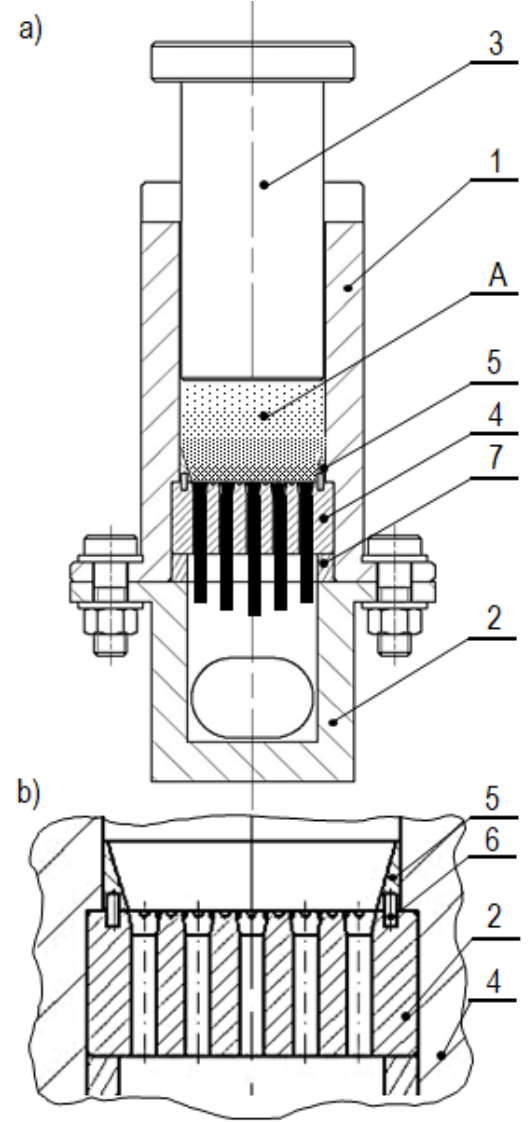

Fig. 10. Test assembly a) test assembly cross-section, b) location of the reducer piece in the test assembly: 1 - extrusion tube, 2 - base of the test assembly, 3 - piston, 4 - multi-channel die plate, 5 - tube reducer, 6 - locating pin, 7 - spacing ring, A - compressed dry ice snow

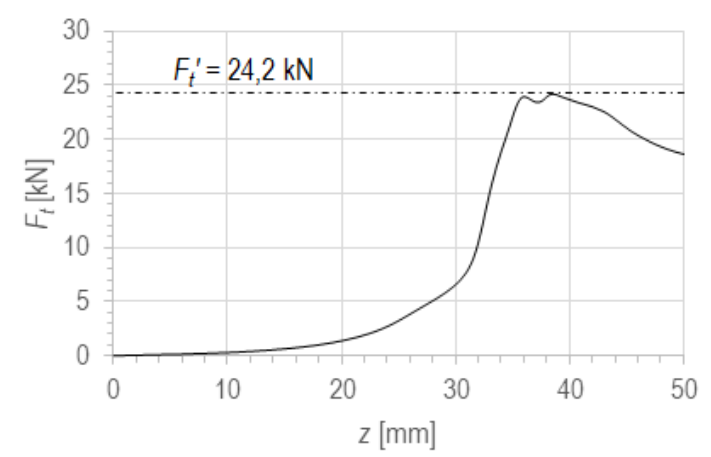

Fig. 11. Compression curve obtained with the multi-channel die plate and compression tube reducer assembly

The average value of the applied force $F_{t}$ ' was $24.2 \mathrm{kN}$. Hence we get a difference of $1,5 \mathrm{kN}$ between the values of $F_{t}$ and $F_{t}$.

\section{SUMMARY}

The tests of the compression tube reducer described in the patent application No. P.419432 have confirmed its influence on the value of the resistance force $F_{O P}$. As it can be figured out from the diagram, the force decreased by $1.5 \mathrm{kN}$ i.e. by ca. $5.8 \%$.

Considering the value of compression stresses in commercial dry ice extrusion machines there is a need for further research in order to build mathematical models describing the relation be- tween the resistance force $F_{O P}$ and the compression tube parameters. These mathematical models will be used to determine the optimum parameters of the compression assemblies of dry ice snow compression machines.

\section{REFERENCES}

1. Chen L., Zhang X. (2014), A review study of solid-gas sublimation flow refrigeration: From basic mechanism to alications, International Journal od Refrigeration, 40, 61-83.

2. Dong S., Song B., Hansz B., Liao H.L., Coddet C., (2012) Modeling of dry ice blasting and its alication in thermal spray, Material Research Innovations, 16, 61-66.

3. Drzymała Z. (1988), Basics of Compaction Engineering of Material Compaction (in polish), PWN, Warsaw.

4. Górecki J., Malujda I., Talaśka K. (2013), Research on Densification of solid carbon dioxide, Journal of Mechanical and Transportation Engineering, 65(4), 5-12.

5. Górecki J., Malujda I., Talaśka K. (2016), Investigation of internal friction of agglomerated dry ice, Procedia Engineering, 136, 275-279.

6. Górecki J., Malujda I., Talaśka K., Kukla M., Tarkowski P. (2016), Influence of the Value of Limit Densification Stress on the Quality of the Pellets During the Agglomeration Process of $\mathrm{CO}_{2}$, Procedia Engineering, 136, 269-274.

7. Li M., Liu W., Qing X., Ye Y., Liu L., Tang Z. Wang H., Dong Y., Zhang H., (2016), Feasibility Study of a New Approach to Removal of Paint Coatings In Remanufacturing, Journal of Materials Processing Technology, 234, 102-112.

8. Liu Y., Calvert G., Hare C., Ghadiri M., Matusaka S. (2012), Size measurement of dry ice particles produced form liquid carbon dioxide, Journal of Aerosol Science, 48, 1-9.

9. Liu Y., Hirama D., Matusaka S. (2012), Particle removal proces during alication of impinging dry ice jet, Powder Technology, 2017, 607-613.

10. Liu Y., Maruyama H., Matsusaka S. (2010), Agglomeration process of dry ice particles produced by expanding liquid carbon dioxide, Advanced Powder Technology, 21, 652-657.

11. Malczewski J. (1992), Mechanic of bulk materials, unit operations (in polish), Warsaw, OWPW.

12. Masa V., Kuba P. (2016) Efficient use of compressed air for dry ice blasting, Journal of Cleaner Production, 111, 76-84.

13. Mazzoldi A., Hill T., Colls J. (2008), $\mathrm{CO}_{2}$ transportation for carbon capture and storage: Sublimation of carbon dioxide from a dry ice bank, International Journal of Greenhouse Gas Control, 2, 210-218.

14. Otto C., Zahn S., Rost F., Zahan P., Jaros D., Rohm H., (2011) Physical Methods of cleaning and Disinfection of Surfaces, Food Engineering Review, 3, 171-188.

15. Patent application No. P.419432, Piston assembly designed for dry ice snow compression, Polish Patent Office, Poland.

16. Spur G., Uhlmann E., Elbing F. (1999), Dry-ice blasting for cleaning: process, optimization and alication, Wear, 233-235, 402-411.

17. UhImann E., Kretzschmar M., Elbing F., Mihotovic V. (2010), Deburring with $\mathrm{CO}_{2}$ Snow Blasting, In: Aurich J., Dornfeld D. (eds) Burrs Analysis, Control and Removal. Springer, Berlin, Heidelberg.

18. Vansant J., (2013), Carbon dioxide emission and merchant market in the European union, In Aresta M. (eds) Carbon Dioxide Recovery and Utilization, Springer Science \& Business Media.

19. Witte A., Bobal M., David R., Blattler B., Schoder D. Rossmanith P. (2017), Investigation of the potential of dry ice blasting for cleaning and disinfection in the food production environment, LWT - Food Science and Technology, 75, 735-741.

20. Yamaguchi H., Niu X., Sekimoto K., Neksa P. (2011), Investigation of dry ice blockage in an ultra-low temperature cascade refrigeration system using $\mathrm{CO}_{2}$ as a working fluid, International Journal of Refrigeration, 34, 466-475. 